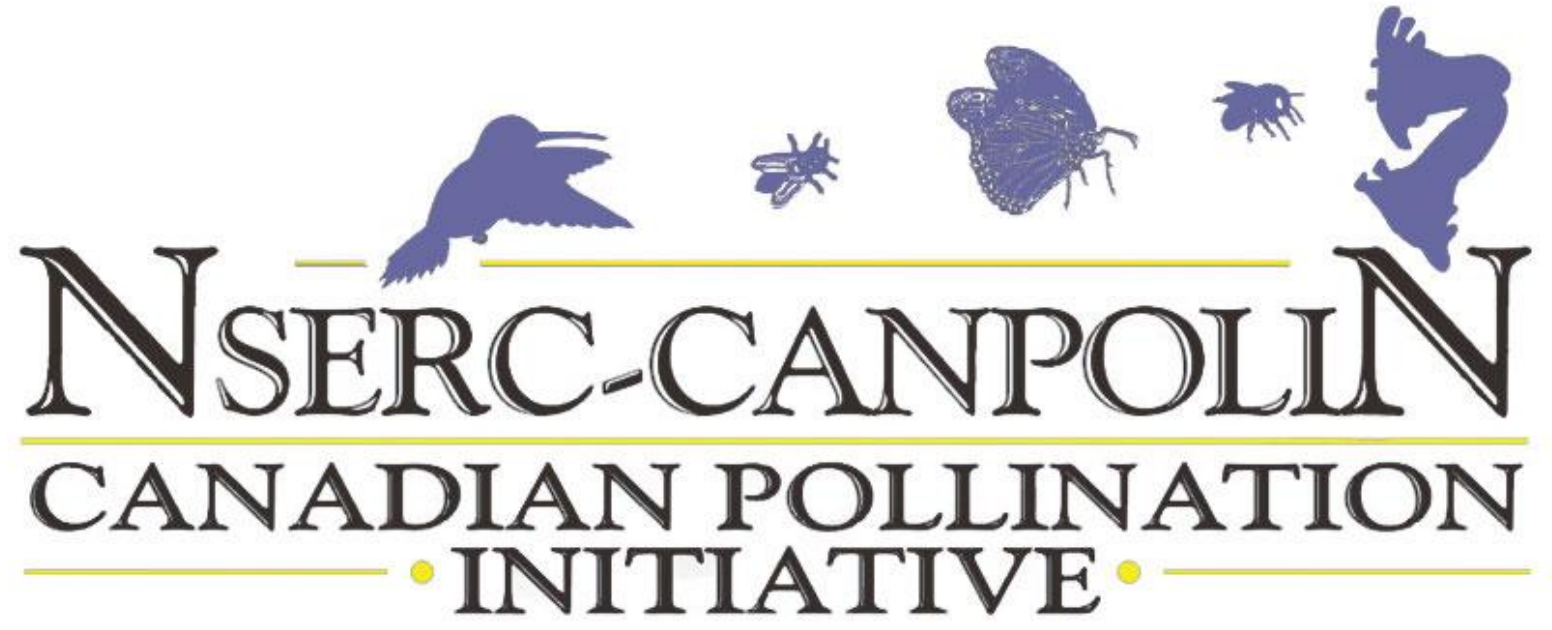

\title{
WHAT IS NSERC-CANPOLIN?
}

NSERC-CANPOLIN is a new, five-year NSERC Strategic Network that will address the growing problem of pollinator decline in agricultural and natural ecosystems in Canada. Researchers at 26 universities across the country are working with government agencies, NGO's and industry to deliver critical insights and sustainable solutions to the pollination problem.

NSERC-CANPOLIN offers an exciting and unique approach to pollination research. For the first time, leading experts in entomology, ecology, plant reproductive biology, genomics, prediction and economics have joined forces to explore the full scope of the pollination problem - from pollinator health and conservation to gene flow in plants, the impact of climate change and the economics of pollination.

\section{Pollinator Decline - The Problem}

In recent decades, biologists have noted a steady decline in the diversity and numbers of pollinators in both managed and natural ecosystems around the world. Recently, the rate of this decline has begun to increase dramatically. Catastrophic losses of honeybees in the United States from the mysterious "Colony Collapse Disorder" have received widespread attention, while beekeepers in Canada are reporting twice the normal amount of winter mortality. Experts suspect that a number of factors are contributing to the loss of managed bee colonies, such as disease, exposure to pesticides, malnutrition and a shifting climate. Wild pollinators are threatened by many of the same issues, as well as habitat loss.

In Canada, most of our wild plants are pollinated by animals (particularly insects), as well as several of our major crops. The continued loss of pollinators threatens both the health of our ecosystems and the production of our food. A much greater understanding of pollination and the interactions between pollinators and their envionment is urgently needed.

\section{WHAT WILL NSERC-CANPOLIN DO?}

NSERC-CANPOLIN will benefit all Canadians by making major contributions to the conservation of pollinator and plant biodiversity, improving the health of managed bees, enhancing pollination by native pollinators, and improving our knowledge of floral/pollinator interactions and gene flow in plants. The Network will also provide critical information on the economic aspects of pollination, and use a state-of-the art modeling approach to predict future management needs in view of expected changes in climate and land use.

\section{Pollination:}

A Vital Ecosystem

$$
\text { Service }
$$

Animal pollinators include bees, flies, moths, butterflies and birds.

They play a key role in plant reproduction, moving pollen from plant to plant as they forage for food.

Ninety percent of all flowering plants and one third of human food crops require animal pollinators to reproduce

- but these pollinators are facing serious threats in many regions around the world. 
The Network is using an integrated approach to study different themes related to pollination (see below). Each area of research will be addressed by a different Working Group. However, given the cross-cutting nature of the research, there is extensive collaboration and integration between Working Groups.

\section{Expected Deliverables from NSERC-CANPOLIN}

\section{Wild Pollinator Taxonomy \& Conservation}

- Inventory of Canada's most important pollinators.

- User-friendly identification guides

- DNA barcode database for bees and pollinating flies in Canada

- Detailed comparisons of the conservation genetics of the three major orders of pollinating insects (bees, flies and butterflies/moths).

\section{Prediction}

- Novel, species-specific models of how pollinator range and abundance may change in response to a shifting climate and changes in land use, and the economic consequences of such change.

- Spatially-explicit recommendations on appropriate management tactics at the regional level.

\section{Economics}

- Characterization of the economic impacts of agriculture, trade, climate change and land use change on pollination services in Canada.

- Determination of the costeffectiveness of strategies to improve pollinator health and deployment.

- Policy recommendations to improve the net benefits of the pollination market in Canada.

\section{Health and Efficiency of Managed Pollinators}

- A national diagnostics network for honeybee diseases.

- New treatment technologies for diseases.

- Improved registration guidelines to reduce pesticide impacts on bees.

- Breeding programs to improve disease resistance.

- Identification and development of different pollinator species for use in agriculture.

- Improved understanding and modeling of the effects of multiple stressors on bees.

\section{Ecosystems}

- Information on the major geographic, landscape and biotic factors affecting plant and pollinator diversity across major Canadian ecozones.

- Determination of the effect of pollinator diversity and/or abundance on seed set of wild and cultivated plants.

- Determination of impact of introduced plant species on pollination of native or crop plants.

- Improved recommendations on how to manage pollinator habitat most effectively.

- Elucidation of the role of floral traits in determining successful pollination of important crop species.

\section{Plant Reproduction and Pollinator Foraging}

- A comprehensive compendium of plant mating systems and their pollination requirements in Canada.

- Improved understanding of the role of pollen in gene flow and dispersal.

- Identification of which Canadian plant species, both wild and cultivated, are most threatened by pollinator decline.

- Documentation of the interrelationships between pollinators and flowers.

\section{Abiotic Pollination}

- Baseline data on pollen production, abscission, dispersal and deposition for major wind pollinated species in Canada.

- Forecasting models for pollen allergens.

- Evaluation of crop yields as a function of pollen concentration.

- Determination of effective isolation distance for GMO crops and tree stands.

- Prediction of plant migration and spread of invasive plant species.
For more information please contact:

NSERC-CANPOLIN
Department of Environmental Biology, University of Guelph, Guelph, ON N1G 2W1 (519)824-4120 X58022 canpolin@uoguelph.ca www.uoguelph.ca/canpolin 